\title{
Fem Sensitivity Analyses on the Stress Levels in a Human Mandible with a Varying ATM Modelling Complexity
}

\author{
E. Armentani ${ }^{1}$, F. Caputo $^{2}$ and R. Citarella ${ }^{*}, 3$ \\ ${ }^{I}$ Department of Material and Production Engineering, University of Naples Federico II - Italy \\ ${ }^{2}$ Department of Aerospace and Mechanical Engineering, Second University of Naples - Italy \\ ${ }^{3}$ Department of Mechanical Engineering, University of Salerno - Italy
}

\begin{abstract}
In this work the structural behaviour of a mandible considering a unilateral occlusion is numerically analysed by means of the Finite Element Method (FEM). The mandible, considered as completely edentolous, is modelled together with its articular disks, whose material behaviour is assumed as elastic or hyper-elastic. The mandible model is obtained by computer tomography scans. The anisotropic and non homogeneous bone material behaviour is considered and the loads applied to the mandible are those related to the active muscle groups during unilateral occlusion. The results of FEM analysis are presented mainly in terms of stress distribution on the mandible. Because of uncertainty on the determination of the adopted parameters, a sensitivity analysis is provided, showing the way in which the variation of articular disc stiffness and temporomandibular joint friction coefficient has an impact on the mandible stress peak and occlusal force.
\end{abstract}

Keywords: Mandible, finite element method, articular disc, sensitivity analysis.

\section{INTRODUCTION}

The mathematical modelling of the whole mandible, with the addition of the articular joint, certainly represents a powerful tool for the determination of the stress-strain distribution related to the human masticatory system.

Many studies have strongly simplified the geometry of the joint surfaces, restricting it to a two-dimensional analysis in the sagittal plane [1,2], or neglecting the presence of anatomical components between the surfaces of the joint [3]. Other authors, even if analysing the temporomandibular joint in its three-dimensional configuration, limited their analysis only to a part of the whole mandible [4,5], or considered the whole mandible without explicitly modelling the disks [6], or considered only elastic material behaviour $[7,8]$, whereas the high level of disk compliances requires a consideration of a hyper-elastic material type [9]. Some of the previously mentioned limitations have been overcome by recent works that accurately analyses the articular disc stresses, considering its viscolelastic [10] or poroelastic behaviour [11,12].

In this paper, in continuation of a consolidated research activity by the authors $[6-9,13]$, the structural behaviour of a mandible which included temporomandibular joint, considering the occlusal phase of a unilateral mastication, has been analysed by the finite element method (FEM). The accuracy of the FEM adopted approach can be based also on the comparison between FEM and BEM (Boundary Element Method) results [6-9]. The mandible, considered completely edentulous, is modelled together with the articular disks whose behaviour is modelled alternatively as elastic or

*Address correspondence to this author at the Department of Mechanical Engineering, University of Salerno, Italy; Tel: +39-089964082;

Fax: +39-089964070; E-mail: rcitarella@unisa.it hyper-elastic. The objective is to provide a sensitivity analysis for the stresses in the mandible as influenced by the values of some parameters related to the temporomandibular joint (TMJ), for which there is uncertainty in assessing the precise values. This objective prevents from adopting a more complicate TMJ modelling as done in $[10,11]$, that would ask for a huge computational effort.

Such sensitivity analyses are useful to the dentists in order to assess the importance of retrieving accurate and patient specific values for the parameters under analysis.

The mandible model has been obtained by the reconstruction of an image obtained by a computerised tomography (C.T.) scan.

\section{CAD MODEL}

In this work the file DICOM (Digital Imaging and Communications in Medicines) has been translated by using the MIMICS software, produced by MATERIALISE. The automatic upload of the DICOM images in a CAD environment offered satisfactory results, allowing to visualise the mandible projected on three planes: the sagittal plane, the horizontal plane and the frontal plane (Fig. 1).

Subsequently the images have been modified and refined in order to clear them from the supports on which the patient has been positioned during the C.T. scan and the metal parts, related to fillings with bio-compatible material. Then, the image segmentation phase (regiongrowing) was realised, by a previous calibration of the optimal contrast value (threshold). Once the complete mandible anatomy is defined, it is possible to realise a $3 \mathrm{D}$ reconstruction. This operation is strongly linked to the correct choice of a threshold value that is peculiar of each patient, because the bone density differs for each patient. 

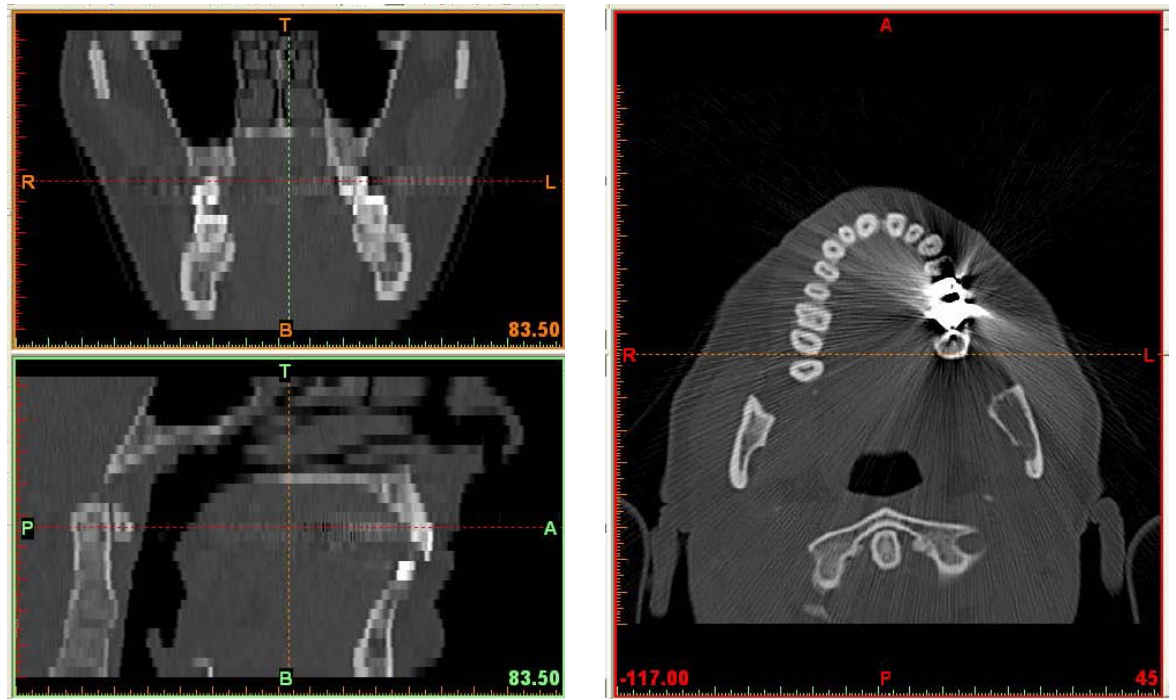

Fig. (1). Projection on sagittal, frontal and horizontal planes of human mandible imported by MIMICS software.

At this point the visualised image is a simple standard triangulation language (STL) representation of the vertex positions and not a mathematical representation of surfaces and volumes. The mathematical reconstruction of the surfaces was then realised by using the MEDCAD module of MIMICS. In this phase it was particularly important to correctly distinguish the parts of cancellous bone from those of cortical bone, because of the nature of the C.T., which does not allow a clear assessment of the layer separating the two materials. Therefore, the contours (polylines) of the objects contained inside the selected mask were generated in an automatic way (Fig. 2) in order to subsequently interpolate them and generate the related surfaces.

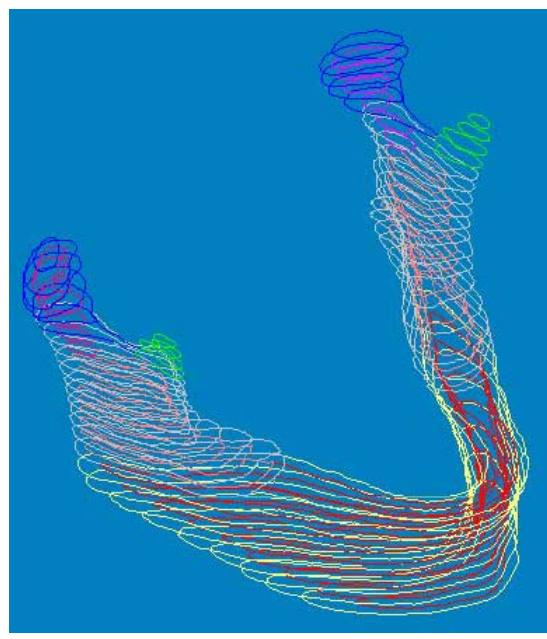

Fig. (2). Twelve sets of polylines (twelve colours) used for generation of mandible geometry.

For the generation of the whole mandible it was necessary to select twelve sets of polylines, seven of which were for the cortical bone parts and five for the cancellous bone parts.

Starting from each of these sets, the corresponding fitting surfaces were automatically produced; in this way twelve surfaces were created, one for each set of polylines (Figs. 3a and $\mathbf{3 b}$ ).

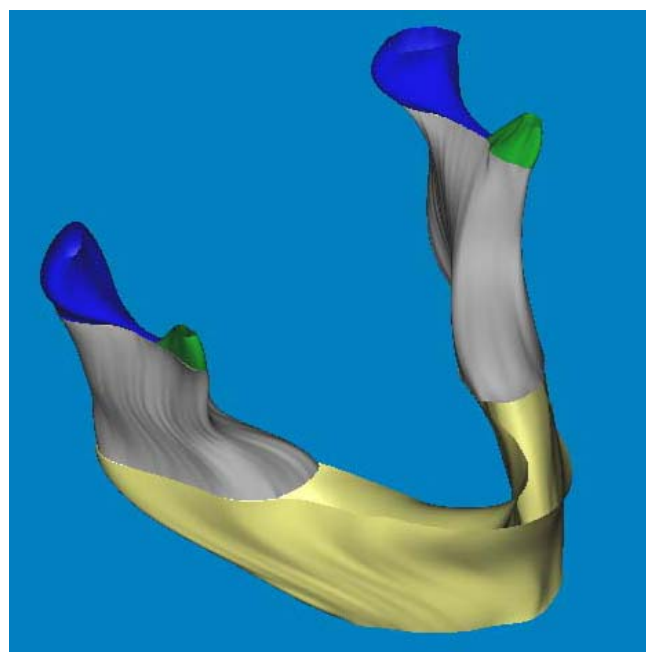

Fig. (3a). Reconstruction of the 7 surfaces related to cortical bone zone.

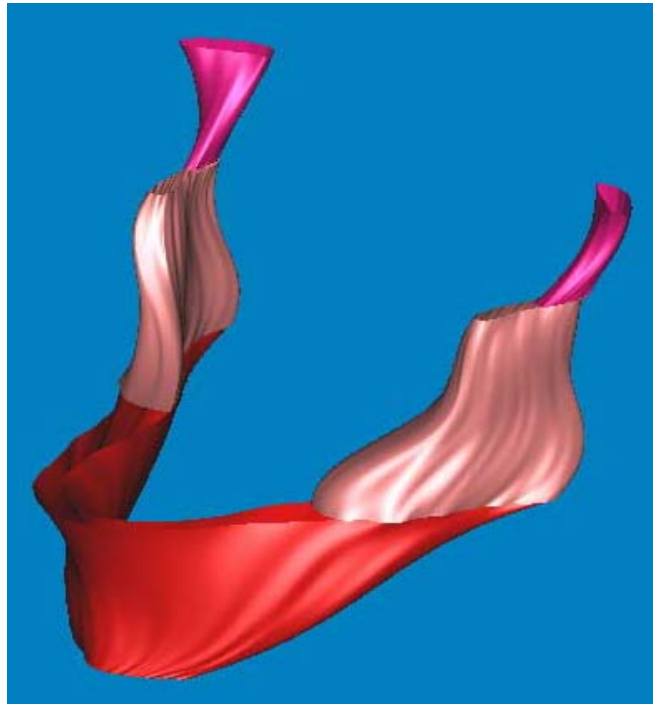

Fig. (3b). Reconstruction of the 5 surfaces related to cancellous bone zone. 
The created geometry was finally exported in an IGES format (Initial Graphics Exchange Specification), that assures the maximum compatibility and the lowest loss of information in the export phase.

The articular disks allow the relative movements within the TMJ, reducing the stress level on the mandible during the masticatory phase. The disks are primarily constituted by cartilage and they are kept in their position by means of the retrodiscal tissue and the constraints imposed by the condyles and the glenoid fossa. The disk geometric reconstruction from C.T. scan was not feasible so it was made from reference to literature data $[2,4]$, but, in order to improve the accuracy of results that are specific to the single patient, it would be better to reconstruct the numerical model of the articular disk by using a Magnetic Resonance and to adapt the estimation of masticatory forces for patient-specific analysis [14].

Considering that the articular disk is positioned between the condyle and the infratemporal cavity and is completely overlapped with the former, it was possible to start their reconstruction from the condyles CAD model.

Once the disk surface was created in contact with the infratemporal cavity (the disk is nearly completely in contact with both the infratemporal cavity and the anterior and superior parts of the condyle), the other four side surfaces embedding the volume of the joint disk and not in contact with other parts of the TMJ were modelled as planar for simplicity (Fig. 4). Actually there is not a fully unloaded state of the disk and this determines a limitation of the modelling approach.

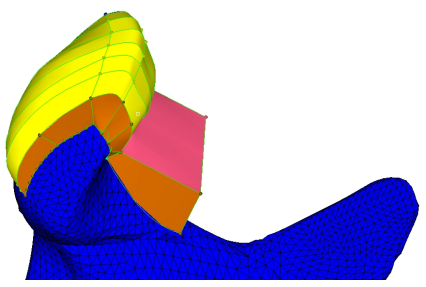

Fig. (4). Disk geometry.

\section{FEM MODEL}

The commercial software used is Ansys. The mandible and related disks were modelled by both tetrahedral 4-noded elements (first model) and hexahedral 8-noded elements (second model). The first model is preferred when there is a need for an automatic pre-processing phase; the second one requires a user intervention but allows a faster solution.
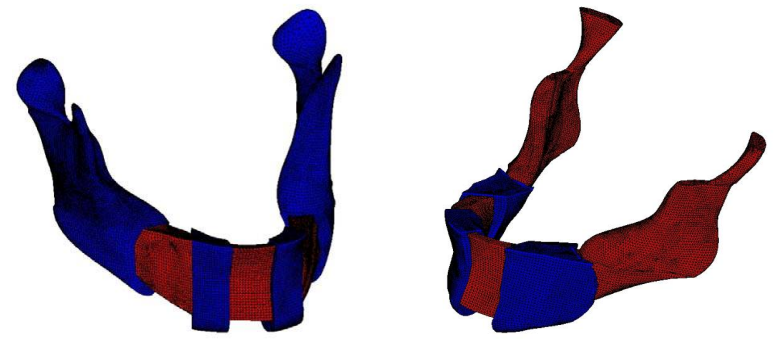

Fig. (5). Tetrahedral FE mesh of mandible (blue colour for cortical zone, red colour for cancellous zone).
Fig. (5) shows the first FE model of the mandible with tetrahedral elements, whereas Fig. (6) shows the second model with hexahedral elements. Figs. (7) and (8) show the FE disk models.
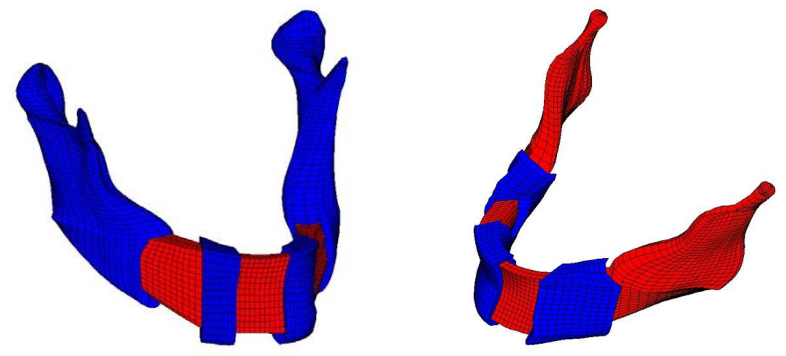

Fig. (6). Hexahedral FE mesh of mandible (blue colour for cortical zone, red colour for cancellous zone).
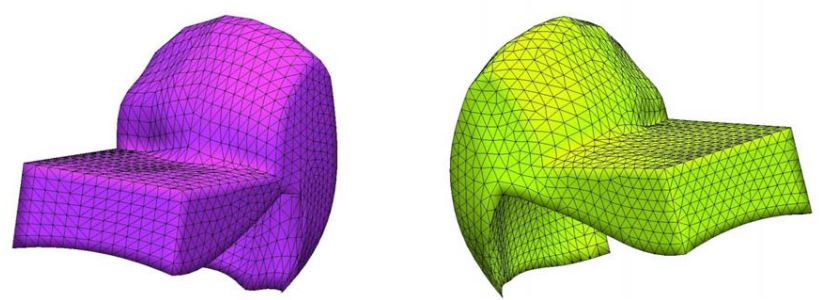

Fig. (7). Tetrahedral FE mesh of ipsilateral (left) and controlateral (right) articular disks.
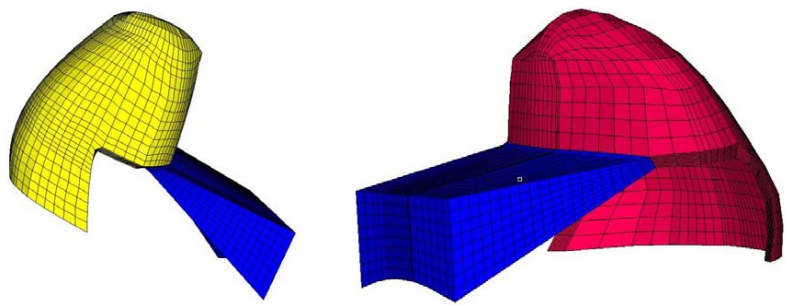

Fig. (8). Hexahedral FE mesh of ipsilateral (left) and controlateral (right) articular disks.

The interaction between the condyles and the joint disks has been modelled by contact elements (contact 173 and target 170 elements from Ansys library). The whole tetrahedral model of the TMJ is characterised by 73,210 nodes and 361,024 elements, 330,596 of which model the mandible and 20,760 the joint disk; 9,668 elements are contact elements interposed between disks and condyle and between disks and infratemporal cavities (Fig. 9a). The hexahedral

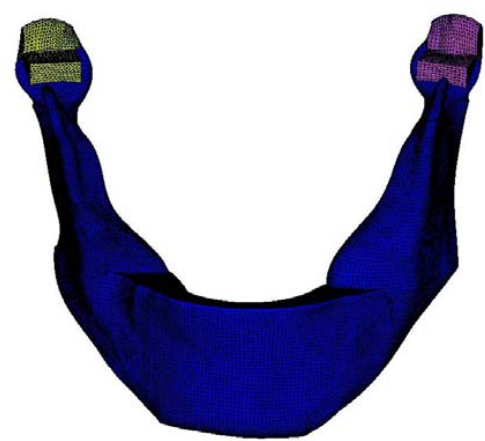

Fig. (9a). Tetrahedral FE mesh of whole temporomandibular joints. 
model is constituted of 16,534 nodes and 18,133 elements (Fig. 9b). The mesh density is in both cases the result of a convergence analysis.

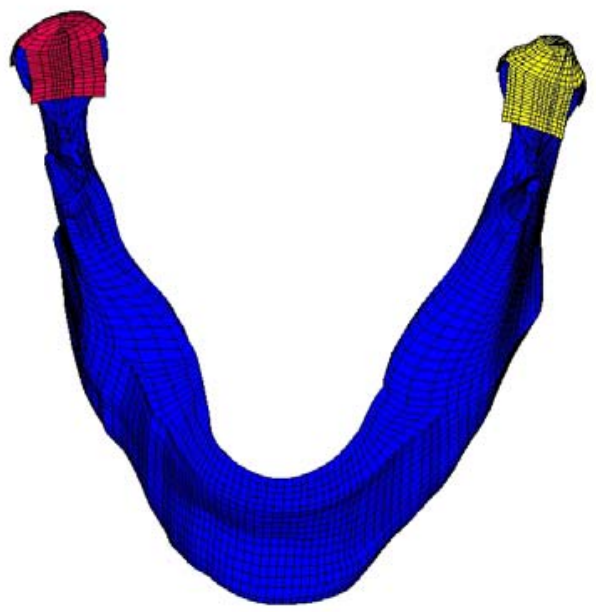

Fig. (9b). Hexahedral FE mesh of whole temporomandibular joints.

The models take into account the non homogeneity and the anisotropy of the bone mandible properties [15-21]. The mandible is divided into an internal zone, where the stiffness is that of the bone cancellous part (Fig. 10a) and an external zone with the material properties of the cortical bone (Fig. 10b). The mandible is further divided in fourteen sectors, characterised by varying stiffness properties (the stiffness increases from the posterior part to the anterior part of the mandible). In each of the considered zones the material has been modelled as transversally isotropic, with specified material directions and elastic compliances (Table 1). With reference to Figs. (10a,b), the global reference system is indicated as xyz, whereas the local material reference system in indicated x'y'z' (z' $\equiv z)$.

The disk material is considered as linear elastic or hyper elastic (large deformations). In the latter case the well known formulation of Mooney-Rivlin for the equation of the deformation energy has been considered:

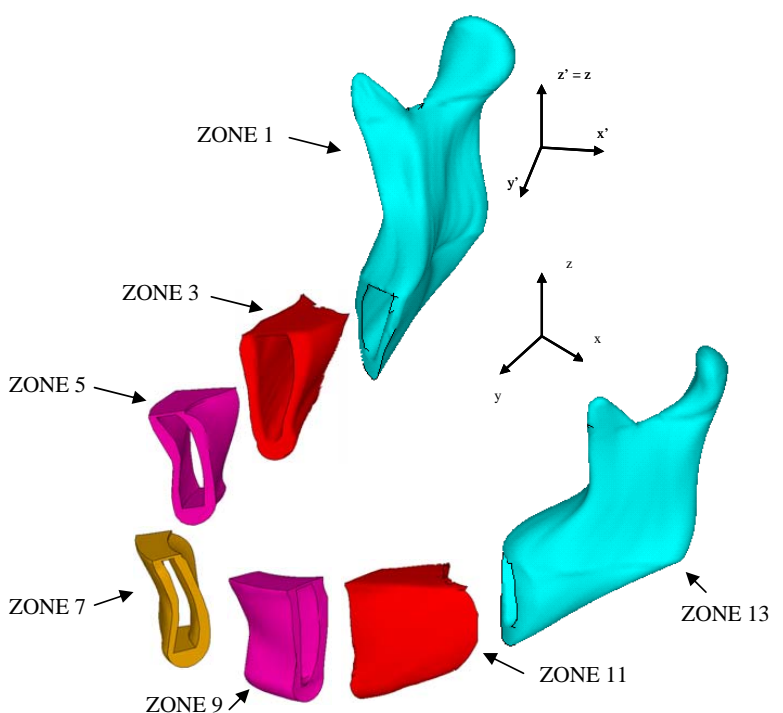

Fig. (10a). Mandible scheme of cortical bone to highlight the different zones considered.

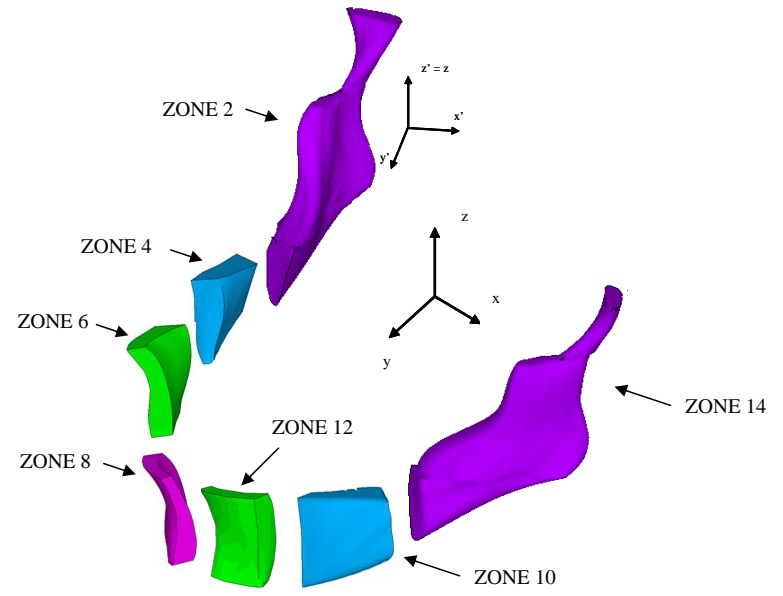

Fig. (10b). Mandible scheme of cancellous bone to highlight the different zones considered.

Table 1. Material Properties and Material Axis Orientations of the Mandible (Zones from 9 to 14 are Symmetric with Respect to Zones from 1 to 6)

\begin{tabular}{|c|c|c|c|c|c|c|c|c|}
\hline ZONE & 1 & 2 & 3 & 4 & 5 & 6 & 7 & 8 \\
\hline$\theta_{x^{\prime}}[$ degrees $]$ & -28 & -28 & -28 & -28 & -59 & -59 & 0 \\
\hline $\mathrm{E}_{\mathrm{x}^{\prime}}[\mathrm{MPa}]$ & $1.00 \mathrm{E}+04$ & $2.42 \mathrm{E}+02$ & $1.22 \mathrm{E}+04$ & $2.78 \mathrm{E}+02$ & $1.36 \mathrm{E}+04$ & $3.46 \mathrm{E}+02$ & $1.35 \mathrm{E}+04$ & $2.94 \mathrm{E}+02$ \\
\hline $\mathrm{E}_{y^{\prime}}[\mathrm{MPa}]$ & $1.00 \mathrm{E}+04$ & $2.42 \mathrm{E}+02$ & $1.93 \mathrm{E}+04$ & $8.35 \mathrm{E}+02$ & $2.40 \mathrm{E}+04$ & $1.04 \mathrm{E}+03$ & $2.04 \mathrm{E}+04$ & $8.83 \mathrm{E}+02$ \\
\hline $\mathrm{E}_{z^{\prime}}[\mathrm{MPa}]$ & $1.68 \mathrm{E}+04$ & $7.27 \mathrm{E}+02$ & $1.22 \mathrm{E}+04$ & $2.78 \mathrm{E}+02$ & $1.36 \mathrm{E}+04$ & $3.46 \mathrm{E}+02$ & $1.35 \mathrm{E}+04$ & $2.94 \mathrm{E}+02$ \\
\hline $\mathrm{G}_{x^{\prime} y^{\prime}}[\mathrm{MPa}]$ & $3.72 \mathrm{E}+03$ & $1.61 \mathrm{E}+02$ & $4.37 \mathrm{E}+03$ & $1.89 \mathrm{E}+02$ & $4.80 \mathrm{E}+03$ & $2.08 \mathrm{E}+02$ & $4.60 \mathrm{E}+03$ & $1.99 \mathrm{E}+02$ \\
\hline $\mathrm{G}_{x^{\prime} z^{\prime}}[\mathrm{MPa}]$ & $4.09 \mathrm{E}+03$ & $5.37 \mathrm{E}+01$ & $4.54 \mathrm{E}+03$ & $1.04 \mathrm{E}+02$ & $5.06 \mathrm{E}+03$ & $1.29 \mathrm{E}+02$ & $5.02 \mathrm{E}+03$ & $1.09 \mathrm{E}+02$ \\
\hline $\mathrm{G}_{y^{\prime} z^{\prime}}[\mathrm{MPa}]$ & $4.09 \mathrm{E}+03$ & $5.37 \mathrm{E}+01$ & $4.37 \mathrm{E}+03$ & $1.89 \mathrm{E}+02$ & $4.80 \mathrm{E}+03$ & $2.08 \mathrm{E}+02$ & $4.60 \mathrm{E}+03$ & $1.99 \mathrm{E}+02$ \\
\hline$v_{x^{\prime} y^{\prime}}$ & $3.45 \mathrm{E}-01$ & $3.45 \mathrm{E}-01$ & $2.36 \mathrm{E}-01$ & $2.36 \mathrm{E}-01$ & $2.36 \mathrm{E}-01$ & $2.36 \mathrm{E}-01$ & $2.36 \mathrm{E}-01$ & $2.36 \mathrm{E}-01$ \\
\hline$v_{x^{\prime} z^{\prime}}$ & $2.36 \mathrm{E}-01$ & $2.36 \mathrm{E}-01$ & $3.45 \mathrm{E}-01$ & $3.45 \mathrm{E}-01$ & $3.45 \mathrm{E}-01$ & $3.45 \mathrm{E}-01$ & $3.45 \mathrm{E}-01$ & $3.45 \mathrm{E}-01$ \\
\hline$v_{y^{\prime} z^{\prime}}$ & $2.36 \mathrm{E}-01$ & $2.36 \mathrm{E}-01$ & $2.36 \mathrm{E}-01$ & $2.36 \mathrm{E}-01$ & $2.36 \mathrm{E}-01$ & $2.36 \mathrm{E}-01$ & $2.36 \mathrm{E}-01$ & $2.36 \mathrm{E}-01$ \\
\hline
\end{tabular}


$W=\sum_{i+j=1}^{N} c_{i j}\left(I_{1}-3\right)^{i}\left(I_{2}-3\right)^{j}+\sum_{k=1}^{N} \frac{1}{d_{k}}(J-1)^{2 k}$

where $W$ is the strain energy potential, $I_{1}$ and $I_{2}$ are the first and the second deviatoric strain invariant, $J$ is the determinant of the elastic deformation gradient, $c_{i j}$ are material constants characterising the deviatoric deformation of the material and $d_{k}$ are material constants characterising the hydrostatics part of the deformation. For relatively small nominal deformations, less than $6 \%$, as it is hypothesised in the case of the disk, $\mathrm{N}$ can be set equal to 1 , for which, in the hypothesis of hyper-elastic incompressible material, eq. (1) becomes:

$\mathrm{W}=\mathrm{c}_{10}\left(\mathrm{I}_{1}-3\right)+\mathrm{c}_{01}\left(\mathrm{I}_{2}-3\right)$.
In this work, according to [2], it has been assumed that $c_{10}=27.91 \mathrm{MPa}$ and $c_{01}=-20.81 \mathrm{MPa}$. The six main muscle groups, activated in the masticatory phase by the occlusal loads are: deep and superficial masseter (DM and SM), medial and lateral pterygoid (MP and LP), and the temporalis muscle, divided into anterior and posterior portions (AT and PT).

The intensity and the direction of the resultant load of every muscle are obtained by experimental measurements, in particular by means of electromyography combined with measurement of the section of the muscular bundles [22]; these results are reported in Table 2. The muscular loads have been modelled as forces applied on the nodes belonging to the surfaces on which the muscular bundles are attached (Figs. 11A and 11B); their values have been obtained by

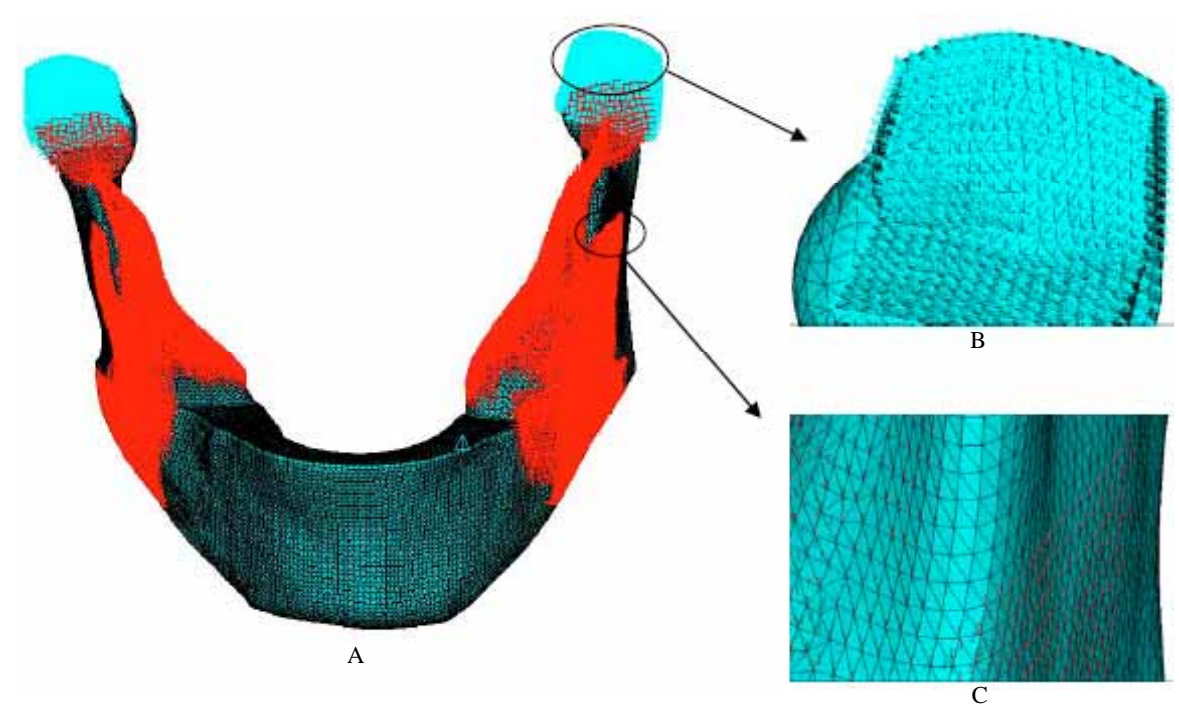

Fig. (11). A) Muscular loads (red) and boundary conditions on disk and occlusal point (blue). B) Close-up of boundary conditions modelling on disk. C) Close-up of muscle loads modelling.

Table 2. Magnitude and Direction of the Mandible Muscle Forces on the left $\left(\mathrm{L}_{\_}{ }_{-}\right)$and Right $\left(\mathbf{R}_{-}{ }_{-}\right)$Side. (PT $=$Posterior Temporalis; AT = Anterior Temporalis; $\mathbf{D M}=$ Deep Masseter; $\mathbf{S M}=$ Superficial Masseter; $\mathbf{M P}=\mathbf{M e d i a l} \mathbf{P t e r y g o i d} ; \mathbf{L P}=$ Lateral Pterygoid)

\begin{tabular}{|c|c|c|c|c|c|}
\hline \multirow[t]{2}{*}{ Muscle } & \multicolumn{3}{|c|}{$\begin{array}{c}\text { Components of the Unit } \\
\text { Force Vector (See Figure 10) }\end{array}$} & \multirow{2}{*}{$\begin{array}{l}\text { Muscle Force } \\
\text { Magnitude [N] }\end{array}$} & \multirow{2}{*}{$\begin{array}{l}\text { Muscle Insertion } \\
\text { Area }\left[\mathrm{mm}^{2}\right]\end{array}$} \\
\hline & $\mathbf{x}$ & $\mathbf{y}$ & $\mathbf{z}$ & & \\
\hline LAT & 0.07 & -0.34 & 0.94 & 27.9 & 363 \\
\hline LDM & -0.27 & 0.18 & 0.94 & 27.3 & 470 \\
\hline LMP & -0.32 & -0.03 & 0.94 & 17.1 & 1199 \\
\hline LLP & 0.25 & 0.94 & -0.25 & 7.4 & 123 \\
\hline RPT & -0.10 & 0.76 & 0.64 & 20.2 & 363 \\
\hline RAT & -0.07 & 0.34 & 0.94 & 21.9 & 363 \\
\hline RLP & -0.25 & 0.94 & -0.25 & 7.4 & 123 \\
\hline
\end{tabular}


dividing the components of the resultant of each muscular load by the number of the involved nodes. Intensity and direction of the muscular actions have been considered as constant during the occlusion. The bite force location, in correspondence of the first molar, has been modelled by imposing a constraint on the mandible in the normal direction to the occlusal plane in correspondence of the considered occlusal point.

The disk is able to slide among the joint surfaces of the condyle and of the infratemporal cavity, being kept in its position by contact forces (the contribution of the retrodiscal tissue attached to the articular disk is neglected because it is very soft). The infratemporal cavity is supposed infinitely rigid and completely constrained (Figs. 11A and 11C).

\section{RESULTS}

The numerical simulations have been primarily oriented to a sensitivity analysis, useful to assess the impact on the mandible stress state of the friction values related to the slippage between disk and condyles and between disk and infratemporal cavity [23]. Moreover the influence of the disk stiffness has been taken into account, by considering hyper elastic material and linear elastic material with different values of Young modulus [24].

All the performed simulations, including those under the hypothesis of linear elastic material for the joint disk and absence of friction, become non linear due to the presence of the contact elements.

Figs. $(\mathbf{1 2 , 1 3 )}$ show the FEM contour plots of von Mises equivalent stress for respectively tetrahedral and hexahedral mandible models (with included TMJ) when considering hyper-elastic disk material properties and TMJ friction coefficient equal to 0.3 .

The results based on tetrahedral and hexahedral models show a level of discrepancy that is not such to affect the main conclusions of the work; so, in the following, only the tetrahedral models are used for sensitivity analyses.
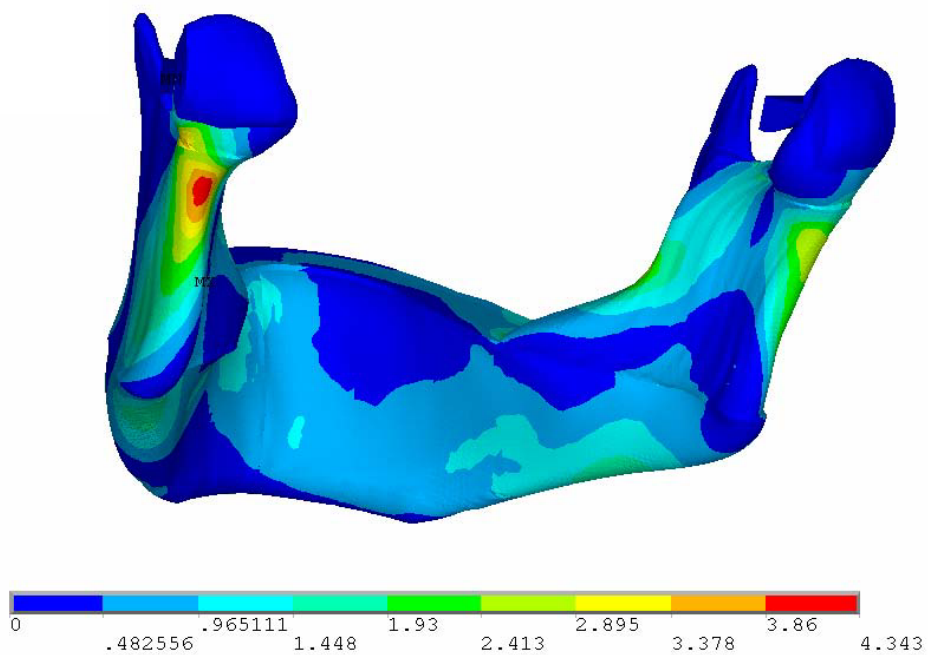

Fig. (12). von Mises equivalent stresses $[\mathrm{MPa}]$ on the mandible and TMJ - tetrahedral model.
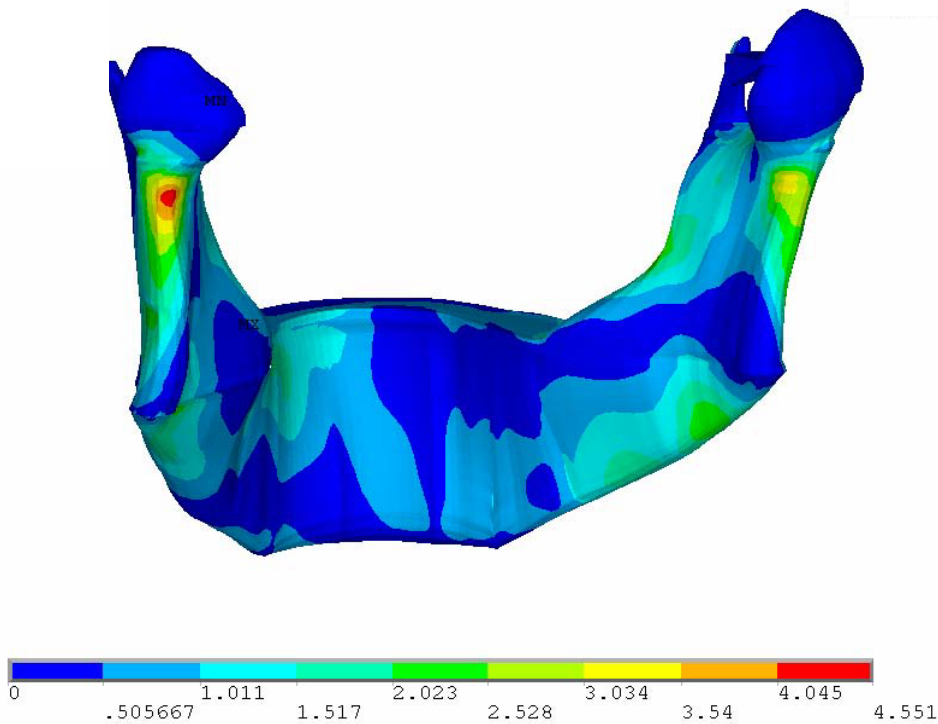

Fig. (13). von Mises equivalent stresses [MPa] on the mandible and TMJ - hexahedral model. 
Fig. (14) shows the sensitivity analyses for the reaction force on the occlusion point against varying values of TMJ friction coefficients and disk material properties (hyper elastic and elastic with different values of the Young modulus). The adopted TMJ friction coefficients reach very high values, typical of a pathologic condition characterised by the absence or reduced effectiveness of synovial liquid. Such reaction force on the occlusal point (bite force) is not strongly influenced by increasing values of friction coefficient or disk stiffness.

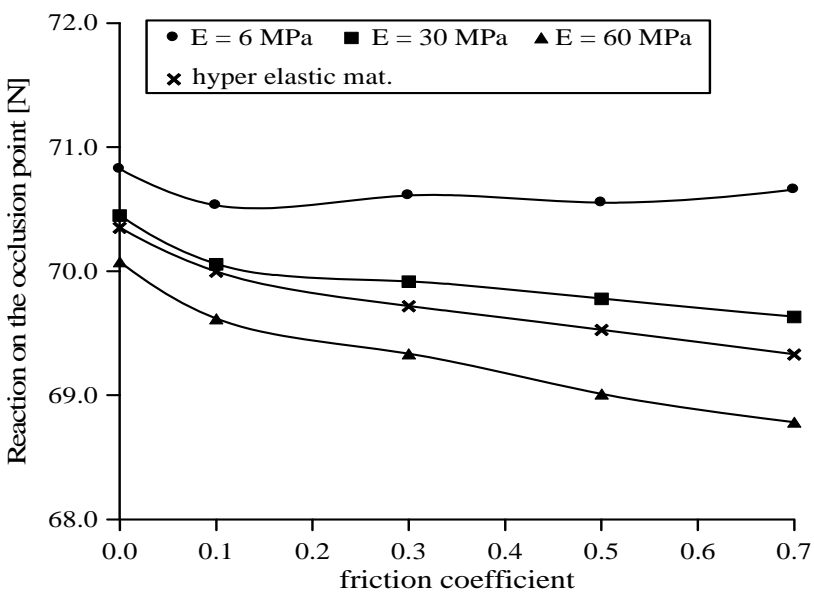

Fig. (14). Reaction on the occlusion point $[\mathrm{N}]$.

On the contrary, the maximum stress (von Mises) in the mandible, which is always located in the area below the ipsilateral condyle (Fig. 15), is affected in non negligible manner by the values chosen for the friction coefficient. Once the loss of lubrication occurs on the joint surface, the mandible appears less stressed.

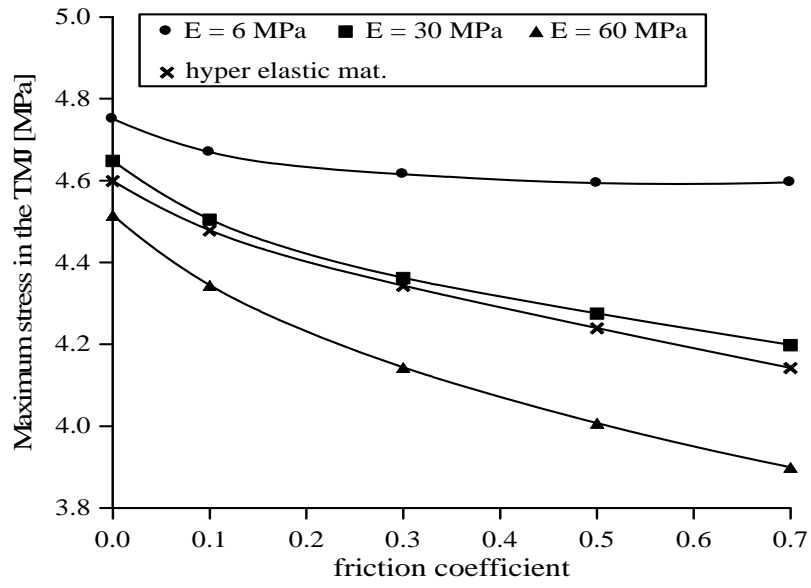

Fig. (15). Maximum stress (von Mises) in the mandible (cortical part) $[\mathrm{MPa}]$.

Within the range of the investigated loads, associated to low deformations values for the disks, it turns out that, considering the mandible bone behaviour and for the chosen hyperelastic parameters, there is a good approximation in modelling the disk material as elastic, with Young modulus equal to $30 \mathrm{MPa}$, instead of a more realistic, but more demanding from a computational point of view, choice of hyper-elastic material properties.

\section{CONCLUSIONS}

Stresses in a mandible undergoing mechanical loading play an important role in different clinical situations (fracture healing, callus stabilisation or transplant healing): their knowledge allow the assessment of the bone regenerative capacity.

Concerning the biomechanics of bones, stress evaluation in different anatomical locations can be used to investigate potential fracture sites under artificial or traumatic loading (e.g. forensic evaluation).

The critical point in these numerical analyses resides in the correct boundary condition evaluation and consequently in the availability of realistic anatomic data like bone density (that is proportional to the stiffness) and muscle forces.

But anyway, based on the obtained results, the following conclusions can be drawn.

Within the range of the muscle forces considered, a more complex modelling of the articular disc material does not considerably affect the reaction force on the occlusal point, whereas the peaks of the mandible stresses are influenced in a non negligible manner by both friction coefficient and disk stiffness values at least considering a non pathological range of TMJ friction coefficient values (less than 0.2).

\section{REFERENCES}

[1] J. Chen, L. Xu, "A finite element analysis of the human temporomandibular joint", Journal of Biomechanics Engineering, vol. 116, pp. 401-407, 1994

[2] J. Chen, U. Akyuz, L. Xu, R. M. V. Pidaparti, "Stress analysis of the human temporomandibular joint", Medical Engineering and Physics, vol. 20, pp. 565-572, 1998.

[3] N. Paydar, H. U. Akay, C. L. Poyraz, W. E. Roberts, "Finite element model of a human mandible for investigating joint reactions and bone stresses during mastication", Advances in Bioengineering, ASME, vol. 20, pp. 163-166, 1991

[4] M. Beek, J. H. Koolstra, L. J. van Ruijven, T. M. G. J. van Eijden, "Three-dimensional finite element analysis of the human temporomandibular joint disc", Journal of Biomechanics Engineering, vol. 33, pp. 307-316, 2000.

[5] R. del Pozo, E. Tanaka, M. Tanaka, M. Kato, T. Iwabe, M. Hirose, $\mathrm{K}$. Tanne, "Influence of friction at articular surfaces of the temporomandibular joint on stresses in the articular disk: a theoretical approach with the finite element method", Angle Orthodontist, vol. 73, no. 3, pp.319-327, 2003.

[6] E. Armentani, C. Calì, F. Caputo, R. Citarella, M. Infante, G. Lavorgna, "Modello agli elementi di contorno per l'analisi tensionale dell'articolazione temporo-mandibolare", in XXXI Convegno Nazionale AIAS Conference Proceedings, Parma, Italy, 2002.

[7] E. Armentani, F. Caputo, R. Citarella, M. Infante, G. Lavorgna, A Naddeo, "Analisi FEM di una mandibola umana con relativa articolazione temporo-mandibolare", in XXXI Convegno Nazionale AIAS Conference Proceedings, Parma, Italy, 2002.

[8] E. Armentani, C. Calì, F. Caputo, R. Citarella, G. Lavorgna "Analisi non lineare FEM e BEM di una mandibola umana in presenza del disco articolare", in XXXII Congresso Nazionale AIAS Conference Proceedings, Salemo, Italy, 2003. 
[9] E. Armentani, F. Caputo, R. Citarella, G. Lavorgna, "Analisi FEM di una mandibola in presenza di disco articolare a comportamento iperelastico", in Convegno Nazionale XIV ADM - XXXIII AIAS Conference Proceedingas, Bari, Italy, 2004.

[10] M. Hirose, E. Tanaka, M. Tanaka, R. Fujita, Y. Kuroda, E. Yamano, T. M. G. J. van Eijden, K. Tanne, "Three-dimensional finite-element model of the human temporomandibular joint disc during prolonged clenching", European Journal of Oral Sciences, vol. 114, pp. 441-448, 2006

[11] A. Pérez Del Palomar, M. Doblaré, “Anterior displacement of the TMJ disk: Repositioning of the disk using a mitek system. A 3D finite element study", Journal of Biomechanical Engineering, vol. 128, no. 5, pp. 663-673, 2006.

[12] A. Pérez del Palomar, M. Doblare, "Finite element analysis of the temporomandibular joint during lateral excursions of the mandible", Journal of Biomechanics, vol. 39, pp. 2153-2163, 2006.

[13] G. Sammartino, G. Marenzi, R. Citarella, R. Ciccarelli, H. L. Wang, "Analysis of the occlusal stress transmitted to the inferior alveolar nerve by an osseointegrated threaded fixture", Journal of periodontology, vol. 79, no. 9, pp. 1735-44, 2008.

[14] M. Koseki, N. Inou, K. Maki, "Estimation of masticatory forces for patient-specific stress analysis of the human mandible", Modelling in Medicine and Biology, vol. 6, pp. 491-500, 2005.

[15] R. S. Hobson, "A pilot study of mineralization distribution in the cortical bone of the human mandible", Archives of Oral Biology, vol. 43, pp. 633-639, 1998.

[16] J. Y. Rho, L. Kuhn-Spearing, P. Zioupos, "Mechanical properties and the hierarchical structure of bone", Medical Engineering \& Physics, vol. 20, pp. 92-102, 1998.
[17] P. Homolkaa, A. Beer, W. Birkfellner, A. Gahleitner, R. Nowotny, H. Bergmann, "Local calibrated bone mineral density in the mandible presented using a color coding scheme", Medical Engineering and Physics, vol. 23, no. 9, pp. 673-677, 2001.

[18] M. Soncini, R. Rodiguez, R. Pietrabissa, V. Quaglini, S. Rizzo, D. Zaffe, "Experimental procedure for the evaluation of the mechanical properties of the bone surrounding dental implants", Biomaterials, vol. 23, pp. 9-17, 2002.

[19] K. Maki, A.J. Miller, T. Okano, Y. Shibasaki, "A threedimensional quantitative computed tomographic study of changes in distribution of bone mineralization in the developing human mandible", Archives of Oral Biology, vol. 46, pp. 667-678, 2001.

[20] C. Verna, B. Melsen, F. Melsen, "Differences in static cortical bone remodeling parameters in human mandible and iliac crest", Bone, vol. 25, no. 5, pp. 577-583, 1999.

[21] R. T. Hart, N. Thongpreda, "A finite element based study of the biomechanics of the mandible", in IEEE Engineering in Medicine and Biology Society 10th Annual International Conference, 1988.

[22] M. G. Faulkner, D. C. Hatcher, A. Hay, "A three-dimensional investigation of temporomandibular joint loading", Journal of Biomechanics Engineering, vol. 20, pp. 997-1002, 1987.

[23] E. Tanaka, M. S. Detamore, K. Tanimoto, N. Kawai, "Lubrication of the temporomandibular joint", Annals of Biomedical Engineering, vol. 36, no. 1, pp. 14-29, 2008.

[24] J. W. deVocht, V. K. Goel, D. L. Zeitler, D. L. Lew, "A study of the control of disc movement within the temporomandibular joint using the finite element technique", Journal of Oral and Maxillofacial Surgeons, vol. 54, pp. 1431-1437, 1996.

This is an open access article licensed under the terms of the Creative Commons Attribution Non-Commercial License (http://creativecommons.org/licenses/by$\mathrm{nc} / 3.0 /$ ), which permits unrestricted, non-commercial use, distribution and reproduction in any medium, provided the work is properly cited. 